\title{
ПРОЦЕСС ОБУЧЕНИЯ ИНДИВИДА В ОРГАНИЗАЦИОННОМ КОНТЕКСТЕ
}

\section{ОРИГИНАЛЬНАЯ СТАТЬЯ}

SILVA, Lilian Reis da ${ }^{1}$

SILVA, Lilian Reis da. Процесс обучения человека в организационном контексте. Revista Científica Multidisciplinar Núcleo do Conhecimento. Год. 06, Изготовить. 10, Вол. 08, с. 17-30. Октябрь 2021 года. ISSN: 2448-0959, Ссылка доступа: https://www.nucleodoconhecimento.com.br/образование-ru/обучениячеловека, DOI: 10.32749/nucleodoconhecimento.com.br/ru/100498

\section{СВОДКА}

Настоящая статья, разработанная на основе библиографрических исследований, ставит в качестве руководящего вопроса вопрос о том, как люди учатся и взаимодействуют в контексте организаций. Цель изучения того, как индивидуальное обучение способствует организационному обучению отдельных людей. Из проанализированной литературы было обнаружено, что знания и знания, полученные индивидуально людьми, должны быть добавлены к навыкам общения, взаимодействия и обмена с коллегами в рамках организаций, чтобы вместе они изучили культуру, внутреннюю систему, цели и присущие ему практики, направленные на достижение поставленных целей.

Ключевые слова: человеческий капитал, знания, навыки, профессиональная эфрфективность, организационное обучение.

\footnotetext{
${ }^{1}$ Аспирант по управлению бизнесом, экономист, бухгалтерская техника.
}

RC: 100498

Доступно в: https://www.nucleodoconhecimento.com.br/oбразование-ru/обучениячеловека 


\section{1. ВСТУПЛЕНИЕ}

На протяжении всей своей профессиональной жизни все люди имеют многочисленные возможности обучения, выходящие за рамки этого обычного и индивидуального - как, например, новые способы работы, которые часто отличаются от одной компании к другой. Такое обучение также может происходить из новых чтений, специализированных курсов или выявления видеороликов в Интернете, по темам, присущим сфере деятельности. Существует также сама сеть.

Учитывая объем информации и модернизации, в которые живет глобальное общество, Безерра и Оливейра (2006, s.p.) ссылаться Guns (1998, стр. 7), чтобы подтвердить, что объем информации сегодня настолько велик, что «руководители, менеджеры и работники на переднем крае также сталкиваются с гигантскими объемами информации».

В свою очередь, благодаря валоризации личности в обществе, которое сегодня уже признает, что человеческий капитал является самым ценным активом внутри организаций (CHIAVENATO, 2020), работники оставили эту роль простых исполнителей ранее определенных задач, перейдя к роли внутренних клиентов, которые требуют постоянных обновлений для лучшего выполнения своих функций, результаты которых должны соответствовать целям, установленным руководством таких организаций.

Эта реальность - не столь недавняя - доводит до всех концепцию организационного обучения, которая, согласно Guns (1998, стр. 33, apud BEZERRA и OLIVEIRA, 2006, s.p.), состоит в приобретении «знаний, навыков, ценностей, убеждений и установок, которые увеличивают поддержание, рост и развитие организации».

RC: 100498

Доступно в: https://www.nucleodoconhecimento.com.br/образование-ru/обучениячеловека 
Поэтому целью этой статьи является изучение того, как индивидуальное обучение способствует организационному обучению среди людей.

\section{2. ПРОЦЕССЫ ОБУЧЕНИЯ ИНДИВИДОВ}

Обучение состоит из акта приобретения индивидом знания, поскольку «природа знания такова, что он быстро меняется и что сегодняшние определенности становятся абсурдами завтрашнего дня» (DRUCKER, 1999, стр. 121).

Учиться в постоянно меняющемся мире нелегко, и в наше время важно, чтобы профессионалы из всех областей продолжали учиться. Флери и Флери (2001, apud MENEZES et al., без даты, p. 2) учат, что «обучение рассматривается как процесс изменения, запускаемый различными стимулами, опосредованный эмоциями, которые могут проявляться, а могут и не проявляться в изменении поведения индивида».

Согласно Словарю португальского языка Houaiss (HOUAISS, 2015, стр. 74), обучение - это «действие, продолжительность и опыт, действие изучения ремесла или профессии», а обучение - это «приобретение практических навыков знания, лучшее понимание (чего-то), интуицией, опытом или сосуществованием [...]».

Бруни; Турриони и Стано (2005, р.190), это психологический процесс, который является фундаментальным для выживания человека, что позволяет ему адаптироваться к среде, в которой он живет, и даже покорять моральный, интеллектуальный и профессиональный рост. Менезес et al. (без даты, стр.2) доклад Аббада и Борхес-Андраде (2004, стр. 238), чтобы подчеркнуть, что «обучение является психологическим процессом, который происходит на индивидуальном уровне.

С точки зрения Юлий (2003), великий вопрос, связанный с обучением, заключается в необходимости для людей учиться учиться, чтобы они всегда

RC: 100498

Доступно в: https://www.nucleodoconhecimento.com.br/образование-ru/обучениячеловека 
могли учиться. Бывает, что для обучения индивиды ищут знания через инфрормацию, которая, в свою очередь, позволяет людям достигать новых знаний путем выбора, отбора, усвоения и ассоциации, с целью совершенствования и обучения обучению. Дело в том, что в то время как знание является результатом отбора информации, которая накапливается, то есть знания человека конструируется через то, что он выбирает, основываясь на информации, которую он получает и которой он ему доверяет (JULIO, 2003).

К этим фрактам добавляется появление Интернета, который позволяет людям получать самый разный контент и информацию, в том числе в режиме реального времени, хотя все чаще встречаются многие материалы, которые не соответствуют действительности и, следовательно, не могут добавить какуюлибо ценность для пользователей Интернета.

Согласно Бруни et al. (2005, стр. 190), обучение происходит эффрективно с того момента, как индивид проходит через определенный опыт, поскольку многочисленные мозговые связи, которые происходят, позволяют человеку ассоциировать фракты, произошедшие в его окружении.

В этой перспективе Сенге (2002, р.32) утверждает, что «все обучение связано с действием. Обучение никогда не происходит исключительно через пассивное обучение». Тем не менее, Бруни et al. (2005) объясняют, что именно через взаимодействие между людьми знания расширяются, индивидуально и коллективно. Другим актуальным аспектом, выделенным этими авторами, являются виды обучения, которые добавляют знания индивидам, это: фрормальное или междисциплинарное обучение, а также неформальное обучение, которое происходит во всех местах и различных ситуациях, от наблюдения за обстоятельствами и взаимодействия между людьми.

В этом смысле Менезес et al. (без даты, стр. 4) сообщают, что фрормальное обучение происходит на основе конкретных действий в отношении задач и

RC: 100498

Доступно в: https://www.nucleodoconhecimento.com.br/образование-ru/обучениячеловека 
целей, которые должны быть выполнены, пересказывая по существу «методы, методы, условия и места, указанные ранее и предназначенные для получения знаний, отношений, навыков, поведения и идей». Также по мнению авторов, фрормальное обучение индивидов разрабатывается по методу, содержащему организованные структуры.

В свою очередь, неформальное обучение, хотя актуальность формального обучения для отдельных лиц, в контексте их личной жизни, с точки зрения организационной среды, бесспорна, различные возможности и цели каждой компании сами по себе потребуют от ее сотрудников иметь разные навыки и знания, приобретенные в практической деятельности, как Флаха и Антонелло (2010, apud MENEZES et al., без даты, стр. 4).

В этом смысле Менезес et al. (без даты, стр. 4) доклад Зербини (2007), в котором утверждается, что неформальное обучение состоит из процессов, с помощью которых люди наблюдают за формальными или неформальными разговорами, будь то на рабочих встречах или в непринужденной обстановке.

В противном случае неформальное обучение неформальное обучение имеет место, когда человек имеет - по собственной инициативе и для своего личного и профессионального роста - возможность усвоения новых видений и установок, которые позволят этому человеку изменить свою профессиональную деятельность. Считается, что это «происходит вне учебных планов курсов, образовательных программ или семинаров» (COELHO JÚNIOR иBORGES ANDRADE, 2008, apud MENEZES et al., s. d., p.4).

Еще одним процессом на пути обучения является признание различий между людьми и уважение к другим жизненным переживаниям, которые записываются в их сознании, которые напрямую влияют на поведение этих людей.

RC: 100498

Доступно в: https://www.nucleodoconhecimento.com.br/образование-ru/обучениячеловека 
В этом смысле Романоский и Перанцони (2011) сообщают о важности обучения детей с самого начала принимать различия между людьми, в том, как они есть, думают и действуют; детей следует учить уважать разнообразие, начиная с раннего возраста, до взрослой жизни и даже профессиональной.

Важность каждого индивидуального обучения и признания различий между людьми заключается в том, что в самых разных регионах страны или мира существуют различия в образовании и обучении, получаемом индивидами дома или в школе, различаются привычки, взгляд на жизнь и на ситуации и людей, различается сексуальная ориентация, и многие другие аспекты различны, от одного человека к другому (ROMANOWSKI и PERANZONI (2011).

Эта реальность требует, чтобы различия в восприятии, обучении и поведении разных людей были приняты окружающими, будучи очень важными для жизненной и бизнес-стратегии, потому что хорошие отношения и уважение приводят к большей производительности и конкурентоспособности в бизнессреде.

В связи с этим все же Романоский и Перанцони $(2011$, с.п.) в докладе Перреноуд (2000) говорится, что для того, чтобы узнать что-то новое, каждый человек должен часто подвергаться учебным ситуациям; более того, эти ситуации имеют смысл для этого ученика, и что он может чувствовать и мобилизоваться с ними и для них.

\section{3. КАК РАЗВИВАТЬ ПРОЦЕСС ОБУЧЕНИЯ В УСЛОВИЯХ ОРГАНИЗАТОРСКИХ СПОСОБНОСТЕЙ?}

\section{1 МЕЖДУ СТРОК}

Bce организации, независимо от их структуры или сегмента, имеют организационную культуру, которая, согласно Шиавенато (2010), состоит из

RC: 100498

Доступно в: https://www.nucleodoconhecimento.com.br/образование-ru/обучениячеловека 
«привычек и убеждений, установленных нормами, ценностями, отношениями и ожиданиями, разделяемыми всеми членами организации. Это относится к системе значений, разделяемых всеми членами, и это отличает одну организацию от другой».

В этом смысле Уилберт и Круз (2014, стр. 2) учат, что для того, чтобы компания была эфффективной в своем сегменте деятельности, принципиально важно, чтобы мысли, ценности и действия, принятые в ее контексте, соответствовали различным типам повседневных задач, что позволяет достижить ожидаемые результаты.

Со временем такие специалисты, как Шанлат (1998), исследовали поведение человека, которое касается не только того, что можно наблюдать, поскольку оно также связано с другими аспектами, включая желание, желание и драйв человека. Аналогичным образом, исследователи, специализирующиеся на организационном управлении, разработали поведенческий анализ в организациях, интерес которых заключался в наблюдении за человеческими явлениями с точки зрения психоаналитической культуры, предлагая три линии видения, которые были выбраны Шанлат (1998) и другими авторами:

a) linha de visão do grupo: vista como um sistema social de defesa contra a angústia e depressão, que analisa o comportamento despersonificado que até hoje inspira numerosos trabalhos (CHANLAT, 1998 apud JAQUES);

b) linha de visão do dirigente: uma segunda linha de pesquisa que procura destacar não apenas o papel e a importância que o imaginário exerce nas ações dos dirigentes das empresas, mas também as conseqüências de sua incidência sobre as organizações (CHANLAT, 1998 apud LEVINSON);

c) linha de visão da organização: uma linha que possui uma abordagem na psicologia social, onde vê a relação homem versus conflitos, elucidando até hoje o que - na organização do trabalho - entra em conflito com o funcionamento do aparelho psíquico (CHANLAT, 1998 apud DEJOURS).

RC: 100498

Доступно в: https://www.nucleodoconhecimento.com.br/образование-ru/обучениячеловека 
Эти работы направлены на необходимость осознать, чтобы понять организационную жизнь, важный инструмент управления. Именно благодаря этому обучению мы можем ценить внутреннюю жизнь и привязанность, которые присутствуют в организационной жизни, и то, насколько человеческие отношения фрундаментально отмечены потребностями и волями (SOUZA, 2016).

\section{2 КОМПЕТЕНТНОСТЬ}

Поиск обучения в организациях путем адаптации их знаний, их способности к данной деятельности и их способности принимать решения являются элементами, необходимыми для повышения квалификации сотрудников в организациях, поскольку для каждой занимаемой позиции необходимо, чтобы весь процесс обучения был очень четким, позволяющим работнику хорошую производительность и результаты в пределах ожидаемого (CROZATTI, 1998).

Согласно Мини-словарь Aurélio португальский язык (FERREIRA, 2008, p. 249), термин компетентность определяется как: «способность решать любой предмет, способности, пригодность». Исходя из этого определения, отмечается, что компетентность раскрывает свою силу при захвате, то есть усвоении, понимании и понимании, и когда происходит трансформация мира труда, будь то в компаниях или в обществе.

Определение отдельных тем, необходимых для хорошей работы в каждой профрессии, недостаточно для инноваций или развития новых навыков для компаний. Должность и профессия определяют квалификацию, или знания или знания каждого человека могут быть классифицированы системой образования. Понятие компетентности ищет путь проактивности, будучи всегда впереди, предвосхищая и доминируя над тем, что происходит и что грядет, не ограничивается, следовательно, запасом теоретических и эмпирических знаний, которыми распорядится индивид, так как он не подразумевается в задаче (EBERT; POSSAMAI И SIMON, 2017).

$\mathrm{RC}: 100498$

Доступно в: https://www.nucleodoconhecimento.com.br/образование-ru/обучениячеловека 
Рассматривая компетентность как практический интеллект приобретенных и преобразованных знаний, возникает новый стандарт компетентности, представленный Флери и Оливейрой Жуниор (2001, apud ZARIFIAN, 2001):

a) necessidade de se antecipar aos fatos e às situações: as quais podem - de alguma forma - tumultuar o bom andamento das atividades e a capacidade de resolver as situações e problemas, para garantir o bom andamento do trabalho;

b) necessidade de comunicação e entendimento: do objetivo organizacional usando de empatia, para 0 alinhamento $e$ partilhamento da cultura organizacional e cumprimento das normas da empresa. Neste sentido, Jean François Chanlat (1998) explica que a comunicação é absolutamente necessária, significando inclusive que - na maior parte do tempo - significa transmitir informação, sendo possível essa comunicação de várias maneiras: por meio de atitudes, de gestos, de modos de vestir, por meio de objetos colocados à nossa volta ou que manipulamos, de espaços organizados etc.;

c) noção de um serviço: entender um cliente independente de ser um cliente interno ou externo sempre precisa ser o foco central das atividades e para que isto ocorra, se faz fundamental a comunicação.

Внутри организации работа перестает быть комплексом задач и становится суммой навыков и компетенций, используемых для решения различных ситуаций, поскольку они становятся все более прибыльными и сложными профессиональными навыками. Эта сложность ситуаций делает непредвиденное все более распространенным в повседневной жизни (LIMA; ZAMBRONI-DE-SOUZA и ARAÚJO, 2015).

Размышляя об организации и ее совокупности, а не только в производственной деятельности, основной фокус анализа (FLEURY и OLIVEIRA JÚNIOR, 2001, apud ZARIFIAN, 2001) мы наблюдаем необходимость введения двух других упоминаний, связанных с мутациями в мире труда.

a) âmbito de atuação da organização: local, regional, nacional ou global: as mudanças de operações da empresa, nesses últimos anos em função do processo de globalização têm implicações significativas para a localização e a formação de competências não

RC: 100498

Доступно в: https://www.nucleodoconhecimento.com.br/образование-ru/обучения- 
só em termos da organização. Percebe-se que essa visão está em todos os níveis (com diferentes ponderações e significações), fazendo parte da competência individual;

b) antes da visão estratégica: ficava no topo das organizações, mas atualmente deve estar em diferentes níveis com significação e critério distintos, compondo o perfil da competência individual.

Компетенция личности не является государством, это не только точное знание, но и ставит ее в результате пересечения трех осей: становления человека (его биографии и социализации), его педагогического образования и его профрессионального опыта (FLEURY и FLEURY, 2004, apud LE BOTERF, 1997).

Компетентность - это ответственный способ действовать при таком признании окружающими. Он проявляется в том, что: знание того, как учиться, знание того, как участвовать, принятие ответственности, стратегическое видение, добавление экономической ценности организации и социальной ценности для человека.

Компетенции создают экономическую ценность для организаций, а также свою десятую социальную ценность для личности; таким образом, мы можем сказать, что организационная компетенция - это портфель компетенций, фризических (инфраструктура), фринансовых, нематериальных, корпоративных (человеческие ресурсы), причем последний является тем, что мы считаем большим диффреренциалом, который создает конкурентные преимущества, и таким образом, мы должны иметь конкурентные стратегии, предоставляемые этими ресурсами. Согласно Флери и Флери (2004), «ресурс - это то, что организация имеет или имеет доступ, даже если этот доступ временный [...], компетенция строится из набора« блоков », называемых ресурсами».

Компетентность - это интеллект согласования, смешивания и включения ресурсов в продукты и услуги. Таким образом, конкурентоспособность организации будет полностью увязана во взаимодействии между организационной компетенцией и конкурентной стратегией, ресурсный подход

RC: 100498

Доступно в: https://www.nucleodoconhecimento.com.br/образование-ru/обучениячеловека 
превращает процесс формулирования стратегии и формирования компетенций в круг, который обратную связь (FLEURY и FLEURY, 2004).

Основные компетенции предлагают реальные преимущества для потребителей, преимущества, которые трудно имитировать, и которые дают доступ к различным рынкам, и когда компания определяет свою конкурентную стратегию, она в конечном итоге определяет свои основные бизнескомпетенции и необходимые компетенции каждой функции - организационные навыки (FLEURY и FLEURY, 2004).

С этой точки зрения проверяется, что компании различных организационных компетенций (коллективные компетенции, связанные со средней деятельностью и конечной деятельностью) в нескольких областях; однако лишь немногие из них являются основными компетенциями, то есть они являются теми, которые отличают их и гарантируют устойчивое конкурентное преимущество перед другими организациями. Чтобы считаться важной компетенцией, она должна быть непосредственно связана с организационными процессами обучения, что придает целенаправленность и перепозиционирует конкурентные стратегии (FLEURY и FLEURY, 2004).

Существует три типа стратегии, которые могут быть приняты организациями, с помощью которых компании конкурируют на рынке, согласно Флери и Флери (2004):

a) excelência operacional: empresas que competem baseadas no custo, oferecendo aos seus clientes produtos com o melhor preço e atendimento adequado;

b) inovação no produto: empresas que oferecerem aos seus clientes produtos de ponta, inovando sempre;

c) orientada para clientes: característica de empresas voltadas a atender a demanda de clientes específicos, e antecipar as necessidades desses clientes, em função de sua proximidade com os mesmos.

RC: 100498

Доступно в: https://www.nucleodoconhecimento.com.br/образование-ru/обучениячеловека 
Как только конкурентная стратегия определена, компания может определить основные компетенции бизнеса, а также навыки, необходимые для каждой фрункции. Эта практика позволяет его совету перейти от стратегического уровня к уровню подготовки компетенций человека, компетенций, классифицированных Флери и Оливейра Джуниор (2001) в трех больших блоках, которые включают отношения человека со всей организацией:

a) competências de negócio: relacionadas ao negócio em si, seu mercado, clientes, concorrentes;

b) competências técnico-profissionais: habilidades específicas para a realização de determinada operação;

c) competências sociais: competências necessárias para interagir com as pessoas, entre elas a competência interdisciplinar necessárias a acordos, à comunicação, à liderança, e ao respeito às culturas distintas.

Коммуникация имеет первостепенное значение, поскольку она обеспечивает понимание сообщений другими членами организации; она заключается в способности четко выражать идеи с использованием методов коммуникации, соответствующих каждой ситуации (CHIAVENATO, 2000).

Через общение человек должен иметь возможность обсуждать, стимулировать и положительно влиять на других людей для эффрективного сотрудничества, чтобы достичь организационных целей, проводя процессы консенсуса, сосредотачиваясь на удовлетворительных результатах для вовлеченных сторон и, главным образом, для организации. Такие инструменты действительны для внешних и внутренних ситуаций, таких как идеальный способ аргументирования, так что он позволяет людям убеждать в продаже идей и принимать расходящиеся точки зрения от их первоначального видения (CROZATTI, 1998).

Командная работа должна создавать и работать с группами людей, обладающих разнообразными и взаимодополняющими навыками и знаниями,

RC: 100498

Доступно в: https://www.nucleodoconhecimento.com.br/образование-ru/обучениячеловека 
обеспечивая появление синергии, которая заключается в способности эфффективно поддерживать совместную работу таких групп, контролировать чрезмерное участие и приглашать молчаливых членов к участию, разрешая конфрликты (CHIAVENATO, 2000).

Дискуссии об обучении в организациях более сильно основаны на интеллектуальной перспективе, свидетельствующей о поведенческих изменениях. То, как люди проявляют и развивают фундаментальные компетенции в рамках организации и еe профрессионального проекта, происходит только в процессе развития их компетенций (CHIAVENATO, 2000). Это совокупность обучающих ситуаций, которые могут привести к трансформации обучения в компетенции; в результате сумма стоимости будет иметь место как для человека, так и для организации.

Это процесс, который может происходить на разных уровнях, как подчеркивают Флери и Флери (2004):

a) ao nível individual: que é onde ocorre primeiro, e como já citado, em um indivíduo que é carregado de emoções positivas ou negativas, por meio dos caminhos que percorreu;

b) ao nível grupal: onde a aprendizagem pode vir a se constituir em um processo social e coletivo, sendo que para compreendê-lo é importante entender como é o aprendizado do grupo, como são integradas as crenças individuais com o grupo e, como transformam esse compartilhamento em ações, além do desejo de pertencer ao grupo, que pode constituir um elemento motivacional ao processo de aprendizagem;

c) em nível organizacional: o processo de aprendizagem individual, de compreensão e interpretação compartilhados pelo grupo, torna-se institucionalizado e conhecido em vários mecanismos organizacionais, ou seja, estrutura, regras, procedimentos, e até mesmo em elementos simbólicos, já que, assim como o indivíduo, as organizações também expandem as memórias que possuem informações e as recuperam.

$\mathrm{RC}: 100498$

Доступно в: https://www.nucleodoconhecimento.com.br/образование-ru/обучения- 
На этом этапе стоит проанализировать процессы обучения. Что касается организационного процесса обучения, то именно этот тип подразумевает разработку карт знаний, которые позволяют понять, что происходит во внешней и внутренней среде организации, а также в определении новых процедур, доказывающих эффрективность обучения (FLEURY и FLEURY, 2004).

Для этого организации полагаются на свои системы знаний и памяти, что позволяет им разрабатывать процедуры и процедуры для решения проблем. Такие процедуры видны в организационной памяти.

Изменения в процессе, структурах или процедурах являются показателями того, что обучение произошло, что повышает легкость восстановления этих знаний членами организации. Согласно Флери и Флери (2000), «это молчаливое, иногда бессознательное знание, которое опирается на организационную память». В этом смысле процесс обучения имеет много граней:

a) "Aprendizagem organizacional é um processo de identificação e correção de erros" (ARGYRIS, 1997, p.116 apud FLEURY e FLEURY, 2000, p. 9);

b) "Aprendizagem organizacional significa um processo de aperfeiçoar as ações pelo melhor conhecimento e compreensão" (FIOL E LYLES, 1985, p.803 apud FLEURY e FLEURY, 2000, p. 9);

c) "organizações que aprendem são organizações capacitadas em criar, adquirir e transferir conhecimentos e modificar seus comportamentos para refletir esses novos conhecimentos e 'insights'" (GARVIN, 1993, p.80 apud FLEURY e FLEURY, 2000, p.9);

d) "Uma organização está continuamente expandindo sua capacidade de criar o futuro" (SENGE, 1990, p.14 apud FLEURY e FLEURY, 2000, p.9).

Организация учится, когда ее способность адаптироваться к изменениям ускоряется, что составляет первый шаг в процессе обучения. Желание учиться идет дальше: оно инновационно и плодотворно.

RC: 100498

Доступно в: https://www.nucleodoconhecimento.com.br/образование-ru/обучениячеловека 


\section{4. ЗАКЛЮЧЕНИЕ}

Благодаря анализу теорий, отобранных для разработки этого исследования, проверяется, что процессы обучения включают в себя различные аспекты - как личные, так и профессиональные, так что обучение в организациях развивается в перспективах их направления.

Если, с одной стороны, личный опыт, формальное образование и характеристики личности индивидов сотрудничают для их личностного формирования, они являются элементами, которые будут дополнять характеристики, руководящие принципы и системы работы, существующие в компаниях, и необходимо, чтобы каждый работник (а) адаптировался наилучшим образом, помимо выявления существования возможностей расширения своих навыков и творчества - или нет - в соответствии с организационными ожиданиями.

\section{ИСПОЛЬЗОВАННАЯ ЛИТЕРАТУРА}

BEZERRA, Alan André Aparecido; OLIVEIRA, Ednilson Barbosa de. Aprendizagem Organizacional: a organização que aprende. Artigo publicado em 06 jul 2006. Disponível em: [https://administradores.com.br/artigos/aprendizagem-organizacionala-organizacao-que-aprende]; acesso em 28 mar 2021.

BRUNI, Márcia; TURRIONI, João Batista; STANO, Rita de Cássia Trindade. Abordagens da aprendizagem no contexto organizacional. II Simpósio de Excelência em Gestão e Tecnologia - SEGeT'2005. p. 190-198. Disponível em: [https://www.aedb.br/seget/arquivos/artigos05/274 Abordagens\%20da\%20aprendiza gem\%20no\%20contexto\%20organizacional.pdf]; acesso em 28 mar 2021.

CHANLAT, Jean François. 0 indivíduo na Organização. 1.ed. São Paulo: Atlas, 1998, v.3.

RC: 100498

Доступно в: https://www.nucleodoconhecimento.com.br/образование-ru/обучениячеловека 
CHIAVENATO, Idalberto. Recursos humanos - 0 capital humano das organizações. 11.ed. São Paulo: Atlas, 2020.

, Gestão de pessoas: o novo papel dos recursos humanos nas organizações. 3.ed. Rio de Janeiro: Elsevier, 2010.

CROZATTI, Jaime. Modelo de Gestão e Cultura Organizacional - conceitos e interações. Caderno de Estudos, SP, FIPECAFI, vol. 10, n. 18, maio/ago 1998.

DRUCKER, Peter F. Administrando em Tempos de Grandes Mudanças. São Paulo: Pioneira, 1999.

EBERT, Luis Augusto; POSSAMAI, Cleide Tirana Nunes; SIMON, Vanessa Silveira. Perspectivas profissionais. Indaial: UNIASSELVI, 2017. Disponível em: [https://www.uniasselvi.com.br/extranet/layout/request/trilha/materiais/livro/livro.php? codigo=25048]; acesso em 03 abr 2021.

FERREIRA, Aurélio Buarque de Holanda. Miniaurélio: o minidicionário da língua portuguesa. 7.ed. Curitiba: Positivo, 2008.

FLEURY, Afonso C. C.; FLEURY, Maria Tereza Leme. Estratégias Competitivas E Competências Essenciais: Perspectivas Para A Internacionalização Da Indústria No Brasil. Gestão \& Produção, vol.10, n.2, p.129-144, ago. 2003. Disponível em: [https://www.scielo.br///gp/a/C8hMY4qXzCfGWd4v8VRwXJQ/?lang=pt]; acesso em 28 mar 2021.

FLEURY, M. Teresa Keme; OLIVEIRA JR., Moacir de M. (Coord.). Gestão estratégica do conhecimento: integrando aprendizagem, conhecimento e competências. São Paulo: Atlas, 2001.

$\mathrm{RC}: 100498$

Доступно в: https://www.nucleodoconhecimento.com.br/образование-ru/обучениячеловека 
GUNS, Bob. A organização que aprende rápido: seja competitivo utilizando o aprendizado organizacional. São Paulo: Futura, 1998.

HOUAISS, Antonio; VILLAR, Mauro de Salles; FRANCO, Francisco Manoel de Mello. Pequeno Dicionário Houaiss da Língua Portuguesa. 1.ed. São Paulo: Moderna, 2015.

JULIO, Carlos Alberto. A Magia dos Grandes Negociadores. 1.ed. Rio de Janeiro: Elsevier, 2003.

LIMA, Claudia Maria Pereira de; ZAMBRONI-DE-SOUZA, Paulo César; ARAÚJO, Anísio José da Silva. A Gestão do Trabalho e os Desafios da Competência: uma Contribuição de Philippe Zarifian. Psicologia: Ciência e Profissão, vol. 35, n. 4, p. 1223-1238, 2015.

Disponível em:

[https://www.scielo.br/j/pcp/a/xxL7S4fWDxwkKWmkB4rtTWp/abstract/?lang=pt]; acesso em 28 mar 2021.

MENEZES, Bárbara Sampaio de; CABRAL, Augusto Cézar De Aquino; SANTOS, Sandra Maria dos; SILVA, Maria Naiula Monteiro da. Aprendizagem individual no contexto organizacional: percepção dos estudantes da FEAAC - UFC. Artigo publicado nos Anais do ENGEMA - Encontro Internacional sobre Gestão Empresarial e Meio Ambiente. Disponível em: [http://engemausp.submissao.com.br/17/anais/arquivos/81.pdf]; acesso em 28 mar 2021.

PERRENOUD, Philippe. Dez novas competências para ensinar: convite à viagem. Porto Alegre: Artes Médicas, 2000.

ROMANOWSKI, Caroline Leonhardt; PERANZONI, Vaneza Cauduro. Educação para diversidade humana: respeito às diferenças $e$ valorização da singularidade. EFDeportes.com, Revista Digital. Buenos Aires - Año 16 - № 158 -

RC: 100498

Доступно в: https://www.nucleodoconhecimento.com.br/образование-ru/обучениячеловека 
julho de 2011. Disponível em: [https://www.efdeportes.com/efd158/educacao-paradiversidade-humana.htm]; acesso em 03 abr 2021.

SENGE, Peter M. A Quinta Disciplina: Arte e Prática da Organização que aprende. 10. ed. São Paulo: Best Seller, 2002.

WILBERT, Alison; CRUZ, Hélio Alves da. Cultura e Clima Organizacionais: uma análise na empresa Novo Trigo de Balneário Camboriu/SC. XI SEGeT - Simpósio de Excelência em Gestão e Tecnologia, de 22 a 24 de outubro de 2014. Disponível em: [https://www.aedb.br/seget/arquivos/artigos14/45120574.pdf]; acesso em 28 mar 2021.

Представлено: Март 2021.

Утверждено: Октябрь 2021 года.

RC: 100498

Доступно в: https://www.nucleodoconhecimento.com.br/oбразование-ru/обучениячеловека 